\title{
TRANSACTIONS OF THE ULSTER MEDICAL SOCIETY.
}

Presidential Address.a By Jonn W. Brers, M.A., M.D., President of the Ulster Medical Society; Professor of Midwifery and of Diseases of Women and Children, Queen's College, Belfast; Examiner in Obstetric Medicine, Gynæcology, and Diseases of Children in the Royal University of Ireland; Physician for Diseases of Women to the Royal Hospital, Belfast; Consulting Physician to the Belfast Hospital for Sick Children.

Gentuemen,-Will you allow me to offer you my warmest thanks for the great honour you have done me in electing me President of the Ulster Medical Society. While I regard the compliment as a very high personal one, I know that you also wish to show the importance you. attach to the particular branch of Medicine with which I am connected, and by this public recognition to mark the great estimate you attach to a thorough knowledge of it in this Society. While success in his calling must be an infinite source of gratification to any man, still there can be no honour which to him is so pleasing as that which arises from the good fellowship and kindness of his professional brethren, as he naturally feels that they are best able to judge of his abilities, his character, and his work.

I cannot pass from this subject without a word expressive of my extreme gratitude to the Profession in general for their recent courtesy, as well as for their hearty kindness and sympathy, when 1 offered myself as a candidate for the Chair of Midwifery and of Diseases of Women and Children in Queen s College, Belfast. Permit me to assure you that if any one thing more than another could afford me a stimulus to endeavour by all the means in my power to advance the School of Medicine with which we are all proud to be connected, and which bolds such a high place in our esteem, that incentive would be found in the confidence placed in me by the gentlemen I see before me this evening, and by my professional brethren throughout the North of Ireland. Good fellowship and kindly brotherhood have always been distinguishing features of the medical profession, and these, I trust, will grow and increase among us here in Ulster. For, though we may not with formality turn to any mere code of rules for our guidance, we shall never go wrong in our action if we hold the honour of each other as highly as we do our own, and in every professional difficulty be guided not only by a strict integrity but by an endeavour to do to others simply as we would wish in the same circumstances that they should act to us.

- Delivered to the Members of the Ulster Medical Society at the opening of the Session 1893-94. 
Looking back on the past thirteen years since $I$ became a member of the Ulster Medical Society, one cannot fail to be struck by the changes which have taken place. We miss many of the kindly faces of our older members, who have either occupied this Chair or who have ably taken part in the discussions that from time to time came up at our medical gatherings. Some whose portraits adorn these walls have passed away, and may it not truly be said of many of our brethren, in the language of a member of the profession: "The dignity of a silent memory is not to be undervalued. Who knows whether the best of men be known, or whether there be not more remarkable persons forgot than those that stand remembered in the known account of time. The greater part must be content as though they had not been, to be found in the register of God, not in the record of man."

You have all, no doubt, observed the great change that late years are bringing among us in the direction of specialisation. "Tempora mutantur, nos et mutamur in illis." In other words, we must adapt ourselves to the altered circumstances of life.

Owing to the great activity of scientific and enthusiastic workers, enormous strides are being made in every department of medical science. No one can possibly keep up with all these advances in every direction, and hence from sheer necessity and from want of time (apart altogether from taste or inclination, or from the opportunities afforded by hospital appointments) if we are to keep pace with these advances or continue to make progress, one is forced to pay more particular attention to one branch of the science, while another gives attention to some other. This tendency to specialise, as the learned President of the British Association said in his recent address, "however much we may regret its necessity, is an essential concomitant of progress." Specialisation becomes more marked in large cities like Belfast, where there are numerous hospitals, and where abundant clinical experience can be obtained and the necessary operative dexterity acquired, and where there is a sufficient population to support those who have won a reputation in any of the special branches of medical science. Many think that the method so common in Scotland of medical men getting a sound knowledge of general practice before adopting any specialty is a good one. By following this course a doctor is less likely to take too narrow a view of a case, a fault often laid at the door of specialists. We must never forget how closely the different organs of the body are correlated, and he who from his special training allows himself to think that the only organ to be looked after is an eye, a joint, an uterus, or a liver, will of ten neither be correct in his diagnosis nor effective in his treatment. Our aim should, therefore, be "to know something of everything and at the same time to know everything of something." As an evidence that really good work is being done in the North of Ireland in the different departments of our 
science, I have only to refer to the record of the meetings of this Society, and of the North of Ireland Branch of the British Medical Association. I hope the time is soon coming when we shall publish the full proceedings of both these bodies, each session, in a complete form. Such a volume would form a permanent record of our work, and, in addition to its scientific value, would be an incentive and a stimulus to us all. The only thing that is wanted is a member of the profession who will undertake the difficult and laborious work of editor, and we all know one whose power of work and literary taste mark him out for the post. The honorary officers of both these societies will, $I$ have reason to know, do all in their power to help on this good work, and I venture to hope that a pecuniary grant would be made by both medical societies out of their accumulated surplus which would in accomplishing such an object be admirably spent. I hope that during the present session a beginning will be made in this direction, and that the great objects for which these societies exist-to encourage fellowship in our work, and to stimulate scientific research-may be more than ever promoted. We all know how difficult it is in the activity, hurry, and worry of practice to keep up that real student life which is an absolute necessity to any progress. It is difficult for many of us in our busy lives to find the time to peruse the medical literature with which we should all be familiar, for never in the history of the science of medicine has there been such activity as in recent years. The remarkable advances in our knowledge of chemistry, bacteriology, and experimental research have contributed to this progress, and hence to the scientific medical man the present is an intensely interesting period. The recent lamented death of the distinguished Frenchman, Charcot, has emphasised the advances in our knowledge of nerve diseases. A new light has been thrown on the physiology and pathology of the thyroid gland by recent discoveries with reference to myxoedema, and a disease hitherto regarded as hopeless has become amenable to treatment. In dermatology Dr. Bramwell's case of psoriasis, cured by the administration of thyroid extract, opens up new fields in the therapeutics of the skin. The most casual reader of the daily papers is relieved on finding that a case reported to be cholera is not that disease, from the fact that further careful examination (microscopic and bacteriological) has failed to find the comma bacilius, whilst he forgets, or more probably has never been aware, that his mind has been relieved through the practical application of some of the greatest and most recent discoveries in medicine, and how wonderfully have hygiene and modern progress been vindicated by the way in which medical forethought and skill have battled with this fell disease, keeping it still at bay throughont the entire coast-line of these islands.

What advances ara taking place every day in the surgery of the 
brain, of the chest, and of the abdomen! But if progress has been great in medicine and in surgery, the recent advances in midwifery and in gynæcology are not less remarkable. In gynæcology there has been a special activity of work. The science has become almost entirely surgical, but on many questions relating to diseases of women there has been the greatest divergence of opinion, and occasionally, it must be admitted, rather too much acrimony in their discussion. On no point has the conflict been keener, or the diversity of opinion more marked than on the question of the treatment of the inflammatory affections of the female pelvis-in a word, whether surgical interference is or is not frequently called for in cases of pelvic inflammation. We have on the one hand men of the greatest experience telling us that abdominal section is not required in pelvic peritonitis, except in rare and exceptional cases, while the teaching of another school is that such surgical interference is the correct treatment in the vast majority of cases. The only way in which this marked divergence of opinion can be explained is that our powers of diagnosis have not yet reached that state of perfection that we can tell with accuracy the condition of the parts in every case of pelvic inflammation; and further, we are unable always to be certain whether a swelling is purulent or not. There are not wanting signs that the pendulum which has swung rapidly from the non-interference view to the opposite of very frequent abdominal section in these cases of pelvic inflammation is coming back to an intermediate or stable position. There is no man who has given his views on the question with greater fairness than my friend Dr. Cullingworth, and I think we shall all agree with his conclusions when he says-- I do not for a moment suggest that every case of inflamed Fallopian tubes should be operated upon; on the contrary, I am of opinion that most of them recover without doing so, but there is a large residuum of cases-most of them chronic, some few acute-in which nothing but an operation can savelife. And there is a still larger number of cases where a timely operation rescues the patient from years of misery, incapacity, and chronic invalidism."

We are also indebted to Professor Pozzi for some admirable procedures, by which, in operative interference with the uterine appendages, any healthy portion of the ovaries may be preserved, and in this way the function of menstruation may still be maintained, and a less mutilating operation be performed. But, gentlemen, although, as $I$ have attempted to show, in recent times there has been the greatest activity in gynæcology, it is very remarkable that it is in midwifery that the advances have been most striking. To my mind the greatest progress has been made (1st) in the various means that have been devised for the delivery of living children with comparative safety to the mother in the case of contracted pelves, and (2nd) in our knowledge of the diagnosis and treatment of 
ectopic or extra-uterine pregnancy. For advances in the former we are indebted mainly to the Continental schools, while our knowledge of extra-uterine gestation, both in its clinical and operative bearings, represents one of the greatest triumphs of British surgery. Let me say a word on each of these interesting subjects.

There can be no question that in former times the frequent performance of craniotomy in English practice was very discreditable; and the greater saving of infant life in recent years has been due to three causes-(1st) The introduction of the axis-traction forceps; (2nd) The re-establishment of Cæsarean section as a justifiable operation; and (3rd) The revival of symphysiotomy.

It was in 1877 that Tarnier first announced that he had invented a new forceps, which he claimed would take a proper grasp of the child's head, would allow it to descend in the axis of the pelvis, and would also supply the accoucheur with the means of knowing how to continue his traction suitable to the plane of the pelvis through which the head was passing. A variety of modifications of this instrument has been made. I show you two (Neville's and Milne Murray's). The instrument is specially valuable in the justo-minor or generally contracted pelvis, and even in the flat pelvis $I$ think its use is superior to turning. There is no doubt that the routine use of axis-traction forceps will prevent craniotomy being done in many cases.

There is no more interesting piece of obstetric history than that of the vicissitudes of Cæsarean section. While the operation was practised among the Jews from very early times, the first recorded case was one in 1500 , but the results were very bad. In Vienna for a hnndred years there had not been a single success; in Paris the operation was as unsuccesful, for up to 1873 there had not been anything but failures for the previous 80 years. In England during the eighteenth and part of the ninteenth centuries there was the same dismal record. The Profession, anxious to accept any less dangerous substitute for the Cæsarean section, welcomed the operation introduced by Professor Porro, of Pavia, in 1876, and being modified slightly by Müller, it was approved of by the authorities at Vienna, the then great obstetric school of the Continent, and the Cæsarean operation seemed for ever displaced. But the Porro operation, as it necessitates the removal of the uterus, was a very mutilating one; it did not satisfy obstetricians, and in 1882 Leopold, of Dresden, operated in a new way suggested by Sänger, of Leipzig, and to these two distinguished men we owe the revival of the modern conservative Cæsarean section. The latest available statistics of Leopold are 50 cuses-46 mothers and all the children saved. Murdoch Cameron, of Glasgow, who has simplified the operation, has had 18 cases, with two deaths. The combined mortality of both these operators was nnder 9 per cent. The principal causes for the great success of the modern 
Cæsarean section are the use of aseptic precautions and the accurate suturing of the uterus. The greater experience in abdominal surgery, the fact that the operation is not done as a last resort, and the attention to details are also to be borne in mind.

The Revival of Symphysiotomy.-A student in surgery called Sigault inaugurated this operation in Paris in 1767, and did it successfully for the first time in 1777 on a soldier's wife. The operation was strongly opposed, and was almost forgotten when in 1863 Morisani, of Naples, studied it on the cadaver, and in 1866 performed it successfully on a living woman, and saved her own and the child's life. Having revived it in Italy, he sent Dr. Spinelli, as his ambassador to Paris, and he illustrated it experimentally to the obstetricians there on November 16th, 1891. Professor Pinard took it up warmly, and in 1892 he and his assistants performed symphysiotomy thirteen times at the Clinique Baudelocque with no maternal deaths, and all the children were extracted living; three, however, died shortly afterwards. It is a very remarkable fact that at the Clinique Baudelocque during 1892 out of 1,800 cases Pinard has had no embryotomy in a living fotus. Morisani has had 22 cases. Tarnier approves of it, and, what is most remarkable, Leopold thinks the operation safer than the Crsarean section, and he would now limit the performance of the latter to cases in which the brim conjugate is less than $2 \frac{1}{2}$ inches.

Symphysiotomy is essentially a conservative operation. Morisani says below $2 \frac{3}{4}$ inches conjugate symphysiotomy is not practicable. It seems specially suitable to those classes of cases in which the ineffectual use of the forceps shows that it is impossible to extract the child. It is useful in small or flattened pelves, in rickety pelves, and in those cases where the outlet of the pelvis is contracted. The operation (division of the pubic bones) is not a difficult one, but there is a risk to be specially guarded against-the wounding of the urethra. The essential point in the operation is the division of the symphysis from above downwards, and from before backwards. The pubes must be separated for at least 4 centimetres, and not beyond 7 centimetres ( $1 \frac{1}{2}$ inches to about $2 \frac{3}{4}$ ). Let me make a practical application of these advances. Suppose we are called to a woman in labour, and we find that owing to pelvic narrowness it is impossible for the fœtus to be born per vias naturales, or let us say we have managed to apply the axis traction forceps, and are unable to deliver the child, and that in both cases the child is living, what are we to do? We may perform an operation with certain death to the child and comparative safety to the mother, or we may adopt Cæsarean section with comparative safety to the child, but endangering the life of the mother; or we may take the plan now so popular in the Paris cliniques, of symphysiotomy. The question is still a debatable one; each case must be settled on the merits, and whatever course is adopted the patient 
must be made thoroughly conversant with any risks she has to undergo. I think, however, we may formulate these rules:-

(a.) If the brim conjugate is less than $2 \frac{1}{2}$ inches the modern improved Cresarean section is the best operation.

(b.) If the brim is not less than $2 \frac{3}{4}$ inches then symphysiotomy is practicable, additional room being gained by the section of the pubes; but it is generally in eases where there is not so much contraction as this, but where it is impossible to deliver without embryotomy, that symphysiotomy is suitable.

(c.) Porro's method may be restricted to cases where, owing to tumours (ex-fibroids), it is necessary to remove the uterus.

By these methods the field for craniotomy is much narrowed. It may still be required in cases of contracted pelvis where the child is dead. Its limits are a conjugate of $2 \frac{1}{2}$ to 3 inches, with a lateral measurement of 13 inches. If the child is hydrocephalic it may be needed, and in some cases of accidental hæmorrhage, or where the mother absolutely refuses to allow any of the other methods. But if this mutilating operation has been done once our duty is to put very strongly before her the value of symphysiotomy, or of Cæsarean section, in case she becomes pregnant again.

I turn now to the second great advance in obstetric medicine which reflects the highest honour on the British School-the management of extra-uterine pregnancy. And if I spoke previously of what has been done on behalf of the child, I will now be able to show you that our recent knowledge in the diagnosis and treatment of ectopic pregnancy has added immensely to the saving of the life of the mother.

[Professor Byers then discussed the diagnosis and treatment of tubal pregnancy.]

Gentlemen, I have attempted to put before you some of the greatest obstetric advances of recent years, but some of you may reply, and perhaps with fairness, that many of the procedures that $I$ have described can be done only in hospitals, and therefore can, in many cases, be carried out only by those who have gained a special experience. Let me then ask you to consider, in conclusion, a subject which concerns us all, and in which, I am sorry to say, a great deal yet remains to be done-I refer to the mortality of child-birth. The main causes of death at child-birth are accidents-such as the various forms of ante- and post-mortem hæmorrhage, eclampsia-and puerperal fever. Let me give you some statistics on this question from an interesting paper of Dr. Boxall. We shall take the mortality for two periods before 1860 (from 1847) and since 1880 . It was about this latter date that antiseptics were introduced. Taking the average mortality for 10,000 confinements we find that in London it was, before $1860,54 \cdot 7$, while since 1880 it has fallen to $37 \cdot 4$. In the provinces it was 50.0 before 1860 ; since 1880 it is 48.9 -that is. there is 
no appreciable difference. Examining the two causes of mortality we find that before 1860 in London, from "accidents of child-birth," it was 30.6 , while this has fallen since 1880 to 15.9 . In the provinces it was, from the same cause, $34 \cdot 2$ before 1860 ; it has fallen since 1880 to $23 \cdot 3$ In London, before 1860 , the death-rate from puerperal fever or metria was $24 \cdot 1$. Since 1880 it has fallen to $21 \cdot 5$ In the provinces before 1860 the puerperal fever death-rate was $15 \cdot 8$, since 1880 it has risen to $25 \cdot 6$.

To sum up, the death-rate in the provinces shows no general diminution, while it does in London. Taking the chief causes of the mortality, we find that both in the provinces and in London deaths from the accidents of child-birth have diminished rather more in the capital, from the fact that skilled assistance in these emergencies can be more readily and quickly obtained there. On the other hand, the striking fact is that in London the death-rate for puerperal fever has perceptibly diminished, while in the provinces it has actually increased, for instead of accounting for about one-third, as formerly, it now causes more than half the total mortality. What is the explanation of this striking fact? It is evidently due to the complete alteration that has taken place in the mortality of lying-in hospitals in London since the introduction of the routine use of antiseptics and their more frequent adoption in general practice. In former times maternity hospitals were the hot-beds of puerperal fever. The mortality at certain periods in these institutions reached the awful height of $\mathbf{3 4 4}$ per 10,000 deliveries, and the canse of the death-rate was chiefly puerperal fever, 75 per cent. of the deaths being due to this cause. No wonder that the Profession cried out for the closing of such institutions, but fortunately the Obstetricians, taking a hint from what Lister had done for surgery, applied the same principles to midwifery, although Semmelweis had before in vain suggested them, with the striking result that puerperal fever and other septic processes have been eliminated, and, as has been said by the able Master of the Rotunda in his recent report, the morbidity of the patients is the true test of the efficiency of the measures taken to secure their safety. Sir Wm. Priestley, in his paper read two years ago at the International Congress of Hygiene, calculated that no less than 3,011 lives of mothers had been saved as the result of this new scientific method of treatment. The experience gained from lying-in hospitals shows us clearly that puerperal fever is a preventable disease. We must take them as our models, and aim in private practice at following out the principles adopted there, with, of course, certain modifications. In the modern lying-in hospital Cæsarean section and symphysiotomy and other serious operations can be done with scarcely a rise of temperature, while, notwithstanding the aggregation of patients from the poorest and filthiest parts of a city, puerperal fever is almost unknown. The maternity has become the place of greatest safety for the lying-in woman, while in her home, and that, too, very frequently amongst 
the upper classes, she is still exposed too of ten to many of the risks of child-bearing. Is this difference not due to the fact that the dangers of the hospital are so apparent that every precaution is taken by all who come in contact with the patient to overcome them? When both we ourselves and the nurses working under us (and they who get their experience in maternities are very differently trained now from what they were in former times) take every opportunity for thoroughly disinfecting the hands, instruments, \&c., and, in a word, everything brought in contact with the patient immediately before, during, and after delivery, avoiding frequent vaginal examination, and endeavouring rather to recognise her condition by abdominal palpation, then we may hope that all septic processes will cease, and that the crowning glory of modern obstetrics-the abolition of puerperal fever-will be attained in private practice as it has been in the public maternities. Let me again say, on every doctor, except the pure specialist in other departments, devolves the duty of forestalling and preventing not only puerperal fever, but the many accidents and conplications to which women are liable in child-bearing. We have to watch that those who are expecting to be confined shall be in a condition to sustain the exhausting fatigues and risks of the puerperal state, and endeavour not only to minimise the death-rate, but so to treat each individual case that there shall be less liability to subsequent gynæcological disease. This requires not only experience and practical training, but it demands the most unremitting care on the part of the practitioner.

Our knowledge of many of the diseases accompanying child-birth, though they have been recognised from the earliest times, is still far from perfect. A wide field remains as yet unexplored, let it be ours to devote our best energies to its clinical and pathological inrestigation. However obscure many of these diseases may be in their origin, there can be no doubt that they often leave behind them mischief that is both painful and lasting. It is impossible for us to urge too strongly the importance of the closest attention to this branch of medicine, for, gentlemen, depend upon it, extreme and what may be considered almost exaggerated care on the part of the accoucheur, will certainly have its reward in the most beneficial results to both mother and child.

I must not weary you, however, by dwelling longer on these points, so familiar to every one who hears me. I trust, during the year on which we have entered, this Ulster Medical Society may prove very helpful to the cause we all have at heart-that is, to investigate the diseases and to alleviate the sufferings of our fellow-beings, whether men or women. The same amount of logical thought or of clear facility of expression is not given to each of us, but in this Society, where we all meet on equal terms, if we manifest an eager and sympathetic attention to all that is brought forward, anxious only to find truth, we shall not merely learn much, but we shall each prove an unconscious stimulus to those who 
come to give their experience of the pathology, diagnosis, or treatment of disease. We shall jealously guard the interests of the Society and of the Profession we have adopted, by giving a regular attendance and close attention to all the meetings, taking the utmost pains in our different departments to keep ourselves abreast of all recent progress and of all new discoveries in our science, so that we may impart each his own quota of information, for do we not meet as students to learn by each other's experience, and not only in the interests of medical and scientific research, but that we may have at our disposal more of those resourees which enable a patient who cannot recover to have less acute suffering as this earthly life ebbs slowly away.

\section{BOMBAY CENSUS.}

The Indian Medico-Chirurgical Review for June, 1893, contains a comparison of the results of the three censuses which have been taken in the Bombay Presidency-in 1872, 1881, and 1891. A previons census (in 1862 ) included the city only. "The census of 1872 showed the population to be 16,308,343. A period of 9 years elapsed before the second census was taken. This period was marked by the appearance of famine, more or less severe in several parts of this Presidency in the years 1877 and 1878. The second census was taken soon after the bad years, and the population was enumerated at $16,489,274$, showing an increase of 180,931. From 1881 to 1891 the Presidency enjoyed fairly good years, and the census taken in February, 1891, showed the population to be $18,901,123$, giving an increase of $2,411,849$ in 10 years. Taking the whole period of 19 years, the increase in the population amounts to $2,592,780 . "$ In the city of Bombay the rate of increase of population in 19 years was $275 \cdot 22$ per mille; in the entire Presidency $158 \cdot 98$. Between 1872 and 1881, in consequence of searcity and its consequences, the increase of population was trifling.

\section{LEPROSY IN BRITTANY.}

We learn from the Boston Medical and Surgical Journal, that Dr. Zambaco Pasha, suspecting that "Morvan's Disease" was really true leprosy, visited Brittany to investigate the question, and especially to see Dr. Morvan's patients. The result has been to confirm his opinion that most of the cases described as syringo-myelia and Morvan's disease are cases of leprosy, which in former times was prevalent in Brittany. $\mathrm{He}$ found among the population a considerable number of persons whose hands were deformed and mutilated as in cases of leprosy. In several persons ulcerated and anæsthetic patches were observed on the legs. Cases of undoubted tubercular leprosy were found, with the characteristic leonine aspect, as well as the well-known pigmentary changes. 